\title{
PRAKTIK BALANCED SCORECARD SEKTOR PUBLIK: SISTEM PENGUKURAN KINERJA UNTUK MENINGKATKAN PERFORMA ORGANISASI
}

\author{
Ali Tafriji Biswan \\ Politeknik Keuangan Negara STAN \\ biswan2009@gmail.com \\ Syahirul Alim \\ Pusat Sistem Informasi dan Teknologi Keuangan \\ kingaaalim@gmail.com
}

\begin{abstract}
This study aims to explore performance based on the Balanced Scorecard in the public sector, namely the Center for Information Systems and Financial Technology. Although initially the BSC measurement system was designed for the private sector from the perspective of customer, financial, internal business processes, and learning \& growth, public organizations have also adopted it, of course, with modifications to suit organizational needs. The Ministry of Finance began implementing the Balanced Scorecard in 2007, and until now it has covered all levels of the organization, including the Center for Information Systems and Financial Technology. The study results show a summary of the perspectives into three perspectives of stakeholders (customers), internal business processes, and learning \& growth; The target achievement of the Key Performance Indicators (KPI) based on the BSC can be achieved, thus encouraging improvements and improvements in future performance.
\end{abstract}

Keywords: Performance, Measurement, Perspective, Balanced Scorecard.

\begin{abstract}
ABSTRAK
Studi ini bertujuan mengetahui pengukuran kinerja berbasis Balanced Scorecard pada sektor publik yakni Pusat Sistem Informasi dan Teknologi Keuangan (Pusintek). Walaupun awalnya sistem pengukuran BSC dirancang untuk sektor swasta melalui perspektif pelanggan, keuangan, proses bisnis internal, dan pembelajaran \& pertumbuhan, beberapa organisasi publik juga mengadopsinya, tentu dengan modifikasi untuk menyesuaikan kebutuhan organisasi. Kementerian Keuangan mulai menerapkan Balanced Scorecard pada tahun 2007, dan hingga kini telah mencakup seluruh level organisasi, termasuk pada Pusat Sistem Informasi dan Teknologi Keuangan. Hasil studi menunjukkan peringkasan perspektif menjadi tiga yakni perspektif pemangku kepentingan atau pelanggan, proses bisnis internal, dan pembelajaran \& pertumbuhan; target capaian Indikator Kinerja Utama (IKU) berbasis BSC dapat dicapai, sehingga mendorong perbaikan dan peningkatan kinerja lebih baik masa mendatang.
\end{abstract}

Kata kunci: Kinerja, Pengukuran, Perspektif, Balanced Scorecard. 


\section{PENDAHULUAN}

Bermula Balanced Scorecard itu diperkenalkan Robert S. Kaplan dan David P. Norton pada 1992 sebagai metodologi untuk mengukur kinerja organisasi. Hal ini didasari pada kondisi bahwa pada saat itu penilaian kinerja hanya menggunakan ukuran yang bersifat finansial. Mereka menyadari bahwa para pemimpin organisasi membutuhkan lebih dari sekedar indikator keuangan untuk meningkatkan kinerja. Balanced Scorecard mengukur empat dimensi organsasi yaitu customer, financial, internal business, dan learning and growth. Walaupun awalnya dirancang untuk digunakan pada sektor swasta, banyak organisasi publik yang mengadopsinya, tentu dengan modifikasi untuk menyesuaikan kebutuhan organisasi.

Kementerian Keuangan merupakan organisasi publik pertama yang mengadopsi Balanced Scorecard sebagai metode untuk melakukan pengukuran dan pencapaian kinerja organisasi. Hal ini menindaklanjuti terbitnya Inpres No. 5 (2004) tentang Percepatan Pemberantasan Korupsi. Dalam diktum ketiga Inpres tersebut, disebutkan bahwa indikator dan target kinerja yang ditetapkan oleh kementerian/lembaga dapat menjadi tolak ukur dalam keberhasilan dan pencapaian kinerja. Pelaksanaan reformasi birokrasi ini kemudian dilanjutkan dengan terbitnya Perpres No. 81 (2010) mengenai grand design Reformasi Birokrasi periode 20102025. Perpres ini mendorong kementerian, lembaga, dan pemerintah daerah untuk menjalankan reformasi birokrasi pada organisasi masing-masing. Pada dasarnya reformasi birokrasi bertujuan menumbuhkan tata kelola kepemerintahan yang profesional dan amanah, mewujudkan trust publik (masyarakat) melalui pelayanan kepemerintahan yang terbaik. Untuk mewujudkan tujuan dari reformasi birokrasi tersebut, Kementerian Keuangan memiliki agenda yang berfokus pada penyempurnaan dan penataan tugas fungsinya, penajaman business process, serta pengembangan SDM Kemenkeu.

Dalam rangka pengukuran capaian keberhasilan reformasi birokrasi dan rencana strategis, diperlukan mekanisme pengelolaan kinerja. Kementerian Keuangan telah memutuskan untuk mengadopsi 


\section{Praktik Balanced Scorecard Sektor Publik: Sistem Pengukuran Kinerja untuk Meningkatkan Performa Organisasi}

Balance Scorecard dalam proses pengukuran dan pencapaian kinerja.

Saat ini, manajemen kinerja

Kemenkeu telah terstandar berbasis

Balanced Scorecard yang dituangkan dalam Keputusan Menteri Kuangan

No. 467/KMK.01/2014 "Pengelolaan

Kinerja di Lingkungan Kementerian Keuangan". Tujuan pengaturan ini adalah:

1. merupakan guidance untuk pengelolaan kinerja baik perencanaan maupun penilaiannya sehingga kontribusi kinerja organisasi dan pegawai lebih maksimal;

2. merupakan alat pengendalian manajerial yang berjenjang dari unit pusat sampai dengan unit operasional;

\section{TELAAH LITERATUR}

Tidak semata alat ukur, sejatinya Balanced Scorecard diposisikan sebagai strategic management system (Rafiq, et al., 2020). Balanced Scorecard menerjemahkan perencanaan strategis (renstra) organisasi (visi, misi, dan strategi) menjadi aksi (Senaratha, S.A.C.L, \& Patabendige, 2015) ke dalam empat perspektif: keuangan, pelanggan,
3. menjadi standar penilaian kinerja (performance evaluation) baik bagi organisasi maupun pegawai;

4. sebagai alat bagi untuk pengembangan kompetensi dan karir SDM Kemenkeu.

Sehubungan dengan hal tersebut, studi ini mendeskripsikan penerapan Balanced Scorecard dan karakteristik di dalamnya sehingga diperoleh gambaran yang jelas pada sektor publik. Studi ini mengambil objek studi pengukuran kinerja pada Pusat Sistem Informasi dan Teknologi Keuangan Kementerian Keuangan, bagaimana pencapaian kinerjanya, dan evaluasi kesesuasian penerapan pengukuran dan pencapaian kinerja dengan kerangka Balanced Scorecard.

proses bisnis internal, serta pembelajaran \& pertumbuhan (Türüdüoğlu, Figen, Suner, \& Y1ldırım, 2014). Perspektif keuangan mendiskripsikan ukuran dan indikator ekonomis dari aktivitas pada perspektif lainnya. Perspektif pelanggan merinci pemakai layanan sehingga unit bisnis bisa bertahan di tengah persaingan. Perspektif proses bisnis internal mendeskripsikan 
berjalannya kegiatan bisnis yang meningkatkan nilai bagi pelanggan dan owner. Perspektif pembelajaran \& pertumbuhan (termasuk di dalamnya infrastruktur) merinci kapabilitas organiasi untuk mempertahankan dan meningkatkan bisnis agar bertumbuh secara berkelanjutan. Perspektif pembelajaran \& pertumbuhan menekankan pada tiga faktor utama yaitu kapabilitas SDM, dukungan sistem informasi, dan perilaku personel (motivasi, empowerment, dan keselarasan). Balanced Scorecard bukan hanya merupakan kumpulan ukuran kinerja kritikal, tapi juga menunjukkan penyelarasan strategi manajemen dari level atas ke level bawah (Ayoup, Hazeline, Omar, \& Rahman, 2016). Alat ukur kinerja itu dibentuk dari pernyataan visi, strategi, dan sasaran strategis organisasi. Perlu diperhatikan keseimbangan alat ukur antara indikator hasil dan faktor penyebab (lag-lead indicator), objektif dan subjektif, finansial dan nonfinansial, serta ukuran eksternal dan internal (Jones \& Phil, 2017), (Zizlavsky, 2014)
Terkait pengelolaan kinerja, KMK No. 467 (2014) mendefinsikan kinerja sebagai hasil pelaksanaan pekerjaan sesuai tusi organisasi dalam suatu periode. Perspektif Balanced Scorecard pada Kementerian Keuangan sebagai berikut.

1. Perspektif Pemangku Kepentingan (Stakeholder)

Pada prinsipnya perspektif ini memotret keberhasilan ukuran kinerjaditinjau dari sisi pemenuhan harapan oleh pemangku kepentingan baik internal maupun eksternal organisasi yang langsung atau tidak langsung terkait keluaran dan hasil kinerja organisasi.

2. Perspektif Customer

Berbeda dengan perspektif stakeholder yang cakupannya luas, perspektif customer menekankan pada pemenuhan harapan pelanggan di luar organisasi yang terkait secara langsung pelayanan yang diberikanoleh organisasi.

3. Perspektif Internal Process Penekanan perspektif ini adalah ukuran keberhasilan proses bisnis dalam rangka pelayanan dan penciptaan nilai bagi stakeholder dancustomer pada perspektif 1 dan 2 sebelumnya. 


\section{Praktik Balanced Scorecard Sektor Publik: Sistem Pengukuran Kinerja untuk Meningkatkan Performa Organisasi}

4. Perspektif Pembelajaran dan Pertumbuhan (Learning \& Growth) Pada pokoknya perspektif ini mencerminkan ukuran daya dukung (sumber daya dan infrastruktur)

\section{METODOLOGI PENELITIAN}

Penelitian ini memiliki lingkup terbatas pada rencana strategis dan kinerja organisasi Pusat Sistem Informasi dan Teknologi Keuangan. Pengukuran kinerja yang dibahas pada penelitian ini hanya mencakup Kemenkeu-two, dan tidak mencakup level di bawahnya. Peta stategi yang digunakan mengacu pada kerangka 2017 yang cukup menggambarkan keseluruhan perspektif yang diterapkan di lingkup Kementerian Keuangan. Data penelitian mengacu pada data kualitatif dan kuantitatif yang dikumpulkan dari objek penelitian yaitu Pusat Sistem Informasi dan Teknologi Keuangn. Data sekunder yang dimaksudkan dalam penelitian ini mencakup halhal berikut:

1. dokumen Rencana Strategis Pusintek Kementerian Keuangan

2. dokumen Laporan Kinerja Pusintek Kementerian Keuangan. organisasi untuk menyelenggarakan proses internal (tugas dan fungsinya) sehingga hasil kinerja memenuhi harapan stakeholder dan customer yang disebutkan sebelumnya.

Agar diperoleh data penelitian, digunakan beberapa teknik pengumpulan data berikut.

1. Studi kepustakaan yang merupakan penggalian sumber pengetahuan dan landasan teoretis dari buku teks, publikasi peraturan, artikel ilmiah, dan referensi lain yang terkait objek studi.

2. Penelitian lapangan yaitu pengumpulan data yang diperlukan dalam penelitian melalui penelitian arsip. Salah satu peneliti adalah bagian dari objek studi sehingga memiliki pemahaman cukup baik terkait implementasi Balanced Scorecard di objek studi tersebut. Penelitian ini menggunakan analisis data dengan pendekatan kualitatif deskriptif yang dilakukan dengan langkah-langkah berikut ini. 
1. Identifikasi visi, misi, dan rencana strategi Pusintek Kementerian Keuangan tahun 2015-2019.

2. Analisis pengukuran kinerja objek studi.

3. Analisis pencapaian kinerjanya.

Tujuan studi ini adalah melihat bagaimana penerapan Balance

Scorecard pada pengukuran dan pencapaian kinerja pada objek

\section{HASIL DAN PEMBAHASAN}

Atas dasar PMK 234 (2015), Pusat Sistem Informasi dan Teknologi Keuangan (Pusintek) bertugas dalam pengoordinasian dan pelaksanaan renstra dan kebijakan bidang teknologi informasi dan komunikasi (TIK), pengembangan sistem informasi, pengelolaan layanan TIK, operasional TIK, keamanan informasi dan kelangsungan TIK, pengelolaan layanan data, dan pengelolaan Jabatan Fungsional Pranata Komputer. Secara organisatoris, pertanggungjawaban tusi Kepala Pusintek adalah kepada Menteri Keuangan, melalui Sekretaris Jenderal.

Sebagai landasan pelaksanaan tugas dan fungsinya, Pusintek mempunyai visi "Menjadi penggerak utama penelitian. Pada penelitian ini, diamati praktik pengelolaan kinerja yang diadopsi dari Balanced Scorecard, kemudian dibandingkan dengan kerangka teoretis Balanced Scorecard. Adapun hal-hal dianalisis dalam penelitian ini mencakup rencana strategis dan pencapaian kinerjanya.

transformasi TIK yang berkelanjutan menuju terwujudnya visi Kementerian Keuangan". Dengan adanya visi organisasi yang telah disepakati diharapkan dapat dipahami oleh setiap pegawai di lingkungan Pusintek dan menjadi motivasi dalam melaksanakan tugas yang telah diberikan untuk pencapaian kinerja sesuai dengan harapan.

Untuk keperluan pengukuran capaian tujuan Pusintek, disusun sasaran strategis yakni:

1. Pelaksanaan transformasi kelembagaan TIK yang optimal. Tujuan yang ingin dicapai adalah efektivitas dan efisiensi layanan korporat dengan memperkuat TIK lingkup Kemenkeu.

2. Pengembangan integrasi sistem informasi keuangan. 


\section{Praktik Balanced Scorecard Sektor Publik: Sistem Pengukuran Kinerja untuk Meningkatkan Performa Organisasi}

3. Tujuan yang diharapkan adalah terintegrasinya sistem informasi dan teknologi di lingkungan KementerianKeuangan.

4. Pengelolaan TIK yang andal. Tujuan yang ingin dicapai adalah meningkatkan kualitas pengelolaan dan operasional layanan TIK yang tinggi sehingga mampu mendorong pengelolaan dan layanan keuangan negara yang lebih baik dan memberikan kepuasan layanan bagi stakeholder internal dan eksternal dilingkungan Kemenkeu.

5. Pengelolaan jabatan fungsional pranata komputer.

6. Tujuan yang diharapkan adalah meningkatkan kapabilitas SDM terbaik bidang TIK di lingkungan Kementerian Keuangan.

Dalam menetapkan strategi, Pusintek harus mendukung pelaksanaan strategi Sekretariat Jenderal yang berkaitan langsung dengan tugas dan fungsi Pusintek. Secara umum beberapa strategi yang dipilih terkait langsung dengan tugas pokok dan fungsi Pusintek dalam rangka mengintegrasikan sistem informasi manajemen keuangan adalah:

1. Penyusunan ICT blueprint termasuk di dalamnya arsitektur
TIK dan roadmap TIK Kementerian Keuangan hasil transformasi kelembagaan.

2. Pembangunan dan pengembangan sistem informasi untuk mendukung core business Sekretariat Jenderal.

3. Pengembangan sistem layanan data Kementerian Keuangan.

4. Bertanggung jawab terhadap implementasi sembilan layer portofolio sistem TIK Kemenkeu yakni presentation layer, common application layer, integration layer, data layer, common system layer, network layer, platform layer, security layer, dan system management layer.

Guna menyusun rencana strategis dan pengembangan TIK yang berkualitas, Pusintek melakukan pengembangan TIK di Kementerian Keuangan yang bertujuan untuk mengintegrasikan sistem informasi manajemen keuangan sehingga mampu mewujudkan pemanfaatan TIK yang terpadu dalam manajemen keuangan negara, dan mewujudkan layanan TIK yang andal dalam pengelolaan sistem informasi keuangan yang mendukung kegiatan perencanaan, pelaksanaan, dan pemantauan 
manajemen keuangan negara. Peta

Strategis Pusintek digambarkan

sebagai berikut.

Gambar 1 Peta Strategis Pusintek

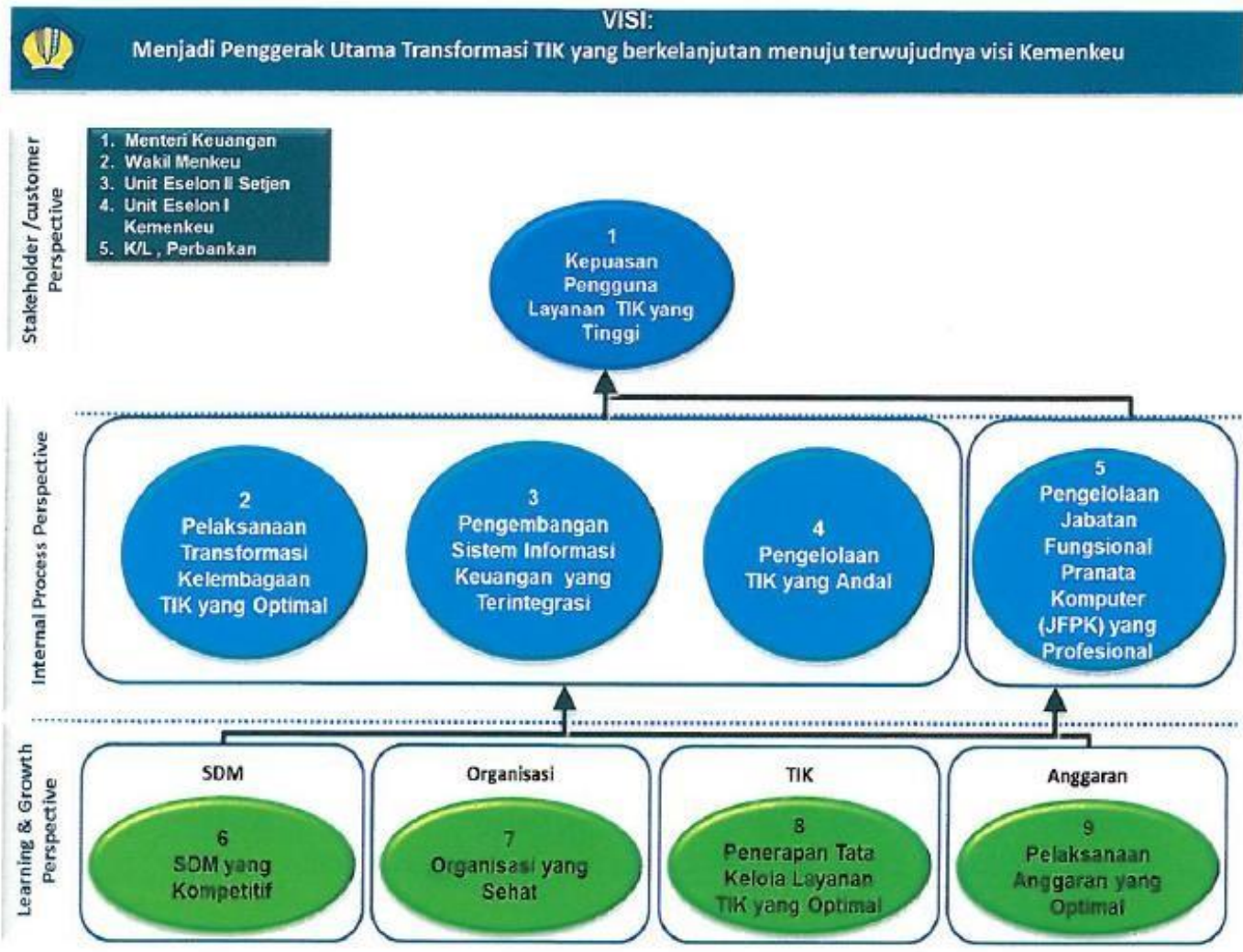

Sumber: Dokumen Rencana Strategis Pusintek 2015-2019

Dapat diamati dari peta strategis

Pusintek tersebut berdasarkan perspektif Balanced Scorecard yakni:

1. Perspektif stakeholder/costumer yang mencakup satu sasaran strategis yaitu Kepuasan pengguna layanan TIK yang tinggi.

2. Perspektif internal process yang mencakup empat sasaran strategis yaitu pelaksanaan transformasi kelembagaan TIK yang optimal, pengembangan sistem informasi keuangan terintegrasi, pengelolaan TIK yang andal, dan pengelolaan jabatan fungsional pranata komputer yang profesional.

3. Perspektif learning \& growth yang mencakup empat sasaran 


\section{Praktik Balanced Scorecard Sektor Publik: Sistem Pengukuran Kinerja untuk Meningkatkan Performa Organisasi}

strategis yakni SDM yang kompetitif, organisasi yang sehat, penerapan tata kelola layanan TIK terbaik, dan penggunaan anggaran yang optimal.

Dalam hal ini dapat diambil simpulan bahwa dalam penerapannya di sektor publik, Balanced Scorecard dapat disesuaikan dengan rencana strategis organisasi. Hal ini selaras dengan studi (Taufik, Rahman, Djamhuri, \&
Saraswati, 2018) bahwa Balanced Scorecard pada sektor publik berbeda dengan sektor privat. Studi (Hidayat, Suryo, Maarif, \& Najib, 2017) juga menemukan bahwa perspektif customer menempati urutan prioritas pada institusi publik. Tabel 1 menunjukkan komparasi penerapan Balanced Scorecard pada Pusintek dibandingkan dengan kerangka teoretisnya.

Tabel 1. Perbandingan Implementasi Balanced Scorecard

\begin{tabular}{|c|c|c|c|c|}
\hline \multirow[b]{2}{*}{ No } & \multirow[b]{2}{*}{ Aspek } & \multicolumn{2}{|c|}{ Balanced Scorecard } & \multirow[b]{2}{*}{ Simpulan } \\
\hline & & $\begin{array}{l}\text { Kerangka } \\
\text { Teoretis }\end{array}$ & $\begin{array}{c}\text { Praktik di Pusintek } \\
\text { Kemenkeu }\end{array}$ & \\
\hline 1 & Kegunaan & $\begin{array}{l}\text { Sistem } \\
\text { manajemen } \\
\text { strategis }\end{array}$ & $\begin{array}{l}\text { Sistem manajemen } \\
\text { strategis, tidak } \\
\text { semata } \\
\text { pengukuran }\end{array}$ & Sama \\
\hline 2 & $\begin{array}{l}\text { Dokumen } \\
\text { awal }\end{array}$ & Rencana strategis & Rencana strategis & Sama \\
\hline 3 & $\begin{array}{l}\text { Proses } \\
\text { penjabaran } \\
\text { stretagi } \\
(\text { cascading }) \\
\end{array}$ & $\begin{array}{l}\text { Visi, misi, } \\
\text { sasaran, tujuan }\end{array}$ & $\begin{array}{l}\text { Visi, misi, sasaran, } \\
\text { tujuan }\end{array}$ & Sama \\
\hline 4 & Perspektif & $\begin{array}{l}\text { Keuangan, } \\
\text { pelanggan, proses } \\
\text { internal, } \\
\text { pembelajaran dan } \\
\text { pertumbuhan }\end{array}$ & $\begin{array}{l}\text { Pemangku } \\
\text { kepentingan atau } \\
\text { pelanggan, proses } \\
\text { internal, } \\
\text { pembelajaran dan } \\
\text { pertumbuhan }\end{array}$ & $\begin{array}{c}\text { Pusintek tidak } \\
\text { menggunakan } \\
\text { perspektif } \\
\text { keuangan }\end{array}$ \\
\hline
\end{tabular}

Berdasarkan data realisasi kinerja, nilai kerja organisasi (NKO) Pusintek sebesar 115,10. NKO yang cukup tinggi berhasil diraih karena kedua puluh Indikator Kinerja Utama (IKU) dapat terealisasi sesuai dan/atau melebihi target yang telah ditetapkan. Berikut ini diuraikan sasaran strategis beserta IKU masing-masing. 
1. Sasaran Strategis Tata Kelola TIK Kementerian Keuangan yang Baik

Peran Pusintek sebagai salah satu supporting unit pada Kementerian Keuangan. Sasaran strategis tata kelola TIK Kementerian Keuangan yang baik diukur melalui tiga IKU dengan penjelasan capaian sebagai berikut.

IKU No. 1a-CP Indeks Implementasi IT Service Management (ITSM) Tahap I.

IKU ITSM merupakan metode pengelolaan pelayanan TIK yang terpusat pada perspektif pengguna layanan TIK. Penerapan ITSM Tahap I diwujudkan dalam bentuk ketersediaan Katalog Layanan TIK Kemenkeu. Katalog ini dikelola unit TIK Pusat dan Unit Eselon I Kemenkeu. Beberapa kegiatan sebagai wujud implementasi ITSM Tahap I sebagai berikut.

a. Pembuatan Katalog Layanan TIK.

b. Penentusn kebijakan penetapan Katalog Layanan TIK Kemenkeu.

c. Penentuan Katalog Layanan TIK Kemenkeu melalui Keputusan Staf Ahli Bidang Organisasi, Birokrasi, dan Teknologi Informasi Nomor 05/SA.8/2017.
IKU No. 1b-N Persentase Penyelesaian Rancangan Peraturan/Keputusan Menteri Keuangan (RPMK/RKMK) Kebijakan sesuai Program Perencanaan RPMK/RKMK.

IKU Penyelesaian RPMK/RKMK Kebijakan merupakan proses pembuatan RPMK/RKMK Kebijakan oleh unit Eselon I dan II konseptor sampai penetapan Menteri Keuangan. Penyelesaian RPMK/RKMK ini mencakup kebijakan dan standar pemeliharaan perangkat TIK, tata kelola TIK, kebijakan sistem manajemen keamanan informasi, pembagian tugas dan tanggung jawab penerapan proses manajemen TIK Kemenkeu.

IKU No. 1c-N Indeks Tindak Lanjut Rekomendasi Hasil Assessment Tata Kelola TIK.

Terhadap asesmen tata Kelola TIK yang dilakukan Inspektorat Jenderal, Pusintek telah melaksanakan hal-hal berikut.

a. Pembahasan rencana tindak lanjut rekomendasi hasil asesmen dengan Subbidang/Bagian terkait di Pusintek.

b. Permbahasan rencana tindak lanjut bersama Tim Audit Itjen. 
c. Menindaklanjuti

semua rekomendasi Itjen.

d. Menyusun laporan hasil tindak lanjut yang telah disetujui oleh Kepala Pusintek.
Tabel 2 menunjukkan sasaran strategis tata kelola Kementerian Keuangan yang baik beserta capaian IKU-nya.

Tabel 2 Sasaran Strategis Tata Kelola dan Capaian IKU

\begin{tabular}{|c|c|c|c|c|}
\hline Kode & Sasaran Strategis/ & \multirow{2}{*}{ Target } & \multirow{2}{*}{ Realisasi } & \multirow{2}{*}{ Nilai } \\
\hline $\mathrm{SS} / \mathrm{IKU}$ & Indikator Kinerja Utama (IKU) & & & \\
\hline Stakehol & ler Perspective (25\%) & & & 30.00 \\
\hline 1 & $\begin{array}{l}\text { Tata Kelola Kementerian Keuangan } \\
\text { yang Baik }\end{array}$ & & & 120 \\
\hline $1 \mathrm{a}-\mathrm{CP}$ & $\begin{array}{l}\text { Indeks Implementasi IT Service } \\
\text { Management Tahap I }\end{array}$ & 100 & 120 & 120 \\
\hline $1 b-N$ & $\begin{array}{l}\text { Persentase Penyelesaian RPMK/RKMK } \\
\text { Kebijakan sesuai Program Perencanaan } \\
\text { RPMK/RKMK }\end{array}$ & $65 \%$ & $100 \%$ & 120 \\
\hline $1 \mathrm{c}-\mathrm{N}$ & $\begin{array}{l}\text { Indeks Tindak Lanjut Rekomendasi } \\
\text { Hasil Assesment Tata Kelola TIK }\end{array}$ & 100 & 100 & 120 \\
\hline
\end{tabular}

Dapat diketahui dari Tabel 2 bahwa sasaran strategis Tata Kelola yang Baik merupakan bagian dari persepktif stakeholder dengan bobot $25 \%$. Ditinjau dari capaiannya, ketiga IKU terealisasi seluruhnya, bahkan ada yang melebihi $100 \%$. Berdasarkan panduan pengelolaan kinerja, capaian maksimal adalah $120 \%$.

2. Sasaran Strategis Terwujudnya Sistem Manajemen Informasi (SIM) yang Andal

SIM yang andal diwujudkan melalui penyelesaian layanan TIK dan gangguan/kendala layanan TIK yang dialami pengguna berdasarkan ketentuan pada Katalog Layanan TIK. Sasaran strategis terwujudnya sistem manajemen informasi yang andal diukur melalui tiga IKU dengan penjelasan capaian sebagai berikut.

IKU No. 2a-CP Tingkat Downtime Sistem TIK.

Dalam IT dikenal downtime system. Dalam hal ini, downtime ditandai dengan terhentinya layanan penting (kritikal) TIK level Eselon I. Umumnya gangguan infrastruktur TIK dan layanan TIK Setjen menyebabkan terjadinya downtime tersebut. Realisasi IKU Tingkat 
Downtime Sistem TIK mencakup kelistrikan, internet, intranet, server, apliaksi, dan database) adalah 0,03\%, melebihi target $0,95 \%$.

IKU No. 2b-CP Jumlah Sertifikasi Standardidasi Internasional terkait

\section{Layanan TIK.}

Sertifikasi

Standardisasi

Internasional yang berkaitan dengan penyelenggaraan layanan TIK antara lain bidang manajemen jasa IT (ISO 20000), bidang sistem manajemen pengamanan informasi (ISO 27001), dan bidang sistem manajemen kualitas (ISO 9000). Pusintek telah melakukan surveillance dalam rangka memastikan bahwa praktik yang tejadi masih sesuai dengan standar yang ada. Menurut Tim Audit Eksternal, pelaksanaan proses bisnis di Pusintek masih sesuai dengan tiga standar ISO tersebut.

IKU No. 2c-N Persentase Integrasi TIK Kementerian Keuangan.

Integrasi TIK merupakan penggabungan atau penyatuan sistem informasi unit-unit Eselon I ke sistem informasi Kemenkeu. Diharapkan dapat terwujud SIM keuangan terpadu (IFMIS). Kegiatan integrasi TIK berhasil dilakukan yakni mencakup pembangunan SLDK,
Integration Module IFMIS Tahap I, dan pengembangan perangkat TIK DC/DRC.

3. Sasaran Strategis Kepuasan Pengguna Layanan TIK yang Tinggi

Kepuasan pemakai layanan menjadi indikasi kualitas layanan TIK di Pusintek sebagai penyedia layanan TIK di Kementerian Keuangan yang mampu memenuhi dan/atau melebihi ekspektasi pengguna layanan. Hal tersebut karena kepuasan pelanggan merupakan sebuah ukuran penting dalam menilai kualitas layanan.

IKU No. 3a-CP Indeks Kepuasan Pengguna Layanan TIK.

Indeks kepuasan pengguna terhadap kualitas dari layanan TIK yang ada pada service katalog merupakan ukuran keterpenuhan layanan TIK Pusintek dapat memenuhi harapan pengguna. Hasil survei layanan desk $(4,55)$, koneksi internet $(4,52)$, surel $(4,31)$, penggunaan software berlisensi $(4,47)$, instalasi desktop atau notebook $(4,52)$, sehingga secara rata-rata hasil survei layanan TIK 4,47 (amat baik), melebihi target 4,25. Tabel 3 menunjukkan sasaran strategis terwujudnya sistem 


\section{Praktik Balanced Scorecard Sektor Publik: Sistem Pengukuran Kinerja untuk Meningkatkan Performa Organisasi}

informasi manajemen dan kepuasan

layanan TIK beserta capaian IKU.

Tabel 3 Sasaran Strategis Terwujudnya Sistem Informasi Manajemen dan Kepuasan Layanan TIK beserta Capaian IKU

\begin{tabular}{|c|c|c|c|c|}
\hline Kode & Sasaran Strategis/ & \multirow{2}{*}{ Target } & \multirow{2}{*}{ Realisasi } & \multirow{2}{*}{ Nilai } \\
\hline SS/IKU & Indikator Kinerja Utama (IKU) & & & \\
\hline Custome & Perpective (15\%) & & & 16.39 \\
\hline 2 & Terwujudnya SIM yang Andal & & & 113.33 \\
\hline $2 \mathrm{a}-\mathrm{CP}$ & Tingkat downtime sistem TIK & $0,95 \%$ & $0,03 \%$ & 120 \\
\hline $2 \mathrm{~b}-\mathrm{CP}$ & $\begin{array}{l}\text { Jumlah sertifikasi } \quad \text { standardidasi } \\
\text { Internasional }\end{array}$ & 3 & 3 & 100 \\
\hline $2 \mathrm{c}-\mathrm{N}$ & Persentase integrasi TIK Kemenkeu & $100 \%$ & $100 \%$ & 120 \\
\hline 3 & Kepuasan Pengguna Layanan TIK yang T & nggi & & 105.18 \\
\hline $3 \mathrm{a}-\mathrm{CP}$ & $\begin{array}{l}\text { Indeks Kepuasan Pengguna Layanan } \\
\text { TIK }\end{array}$ & $\begin{array}{c}4.25 \\
\text { (skala } \\
5)\end{array}$ & 4.47 & 105.18 \\
\hline
\end{tabular}

4. Sasaran Strategis RBTK Bidang TIK yang Efektif, Efisien dan Kredibel

Inisiatif transformasi kelembagaan bidang TIK merupakan sejumlah kegiatan rekomendasi dari jasa konsultasi transformasi kelembagaan. Inisiatif transformasi kelembagaan bidang TIK yang akan diimplementasikan adalah inisiatif yang menjadi tanggung jawab Pusintek dan direkomendasikan untuk dilaksanakan. Tindakan yang telah dilakukan dalam rangka implementasi inisiatif kelembagaan adalah meluncurkan arsitektur estate TIK, menyusun struktur organisasi, proses, dan pengelolaan IT, menentukan anggaran TI, mengembangkan tahapan penyelesaian kendala dan ancaman, menentukan manajemen pemulihan bencana dan prosedur operasionalnya, menyusun $e$ catalogue atas produk TI standar, mengkonsolidasikan kegiatan pemeliharaan TIK, dan mengembangkan training terkait pengelolaan TI Kemenkeu.

5. Sasaran Strategis Pengembangan SIM yang Terintegrasi

Sasaran strategis ini pada dasarnya harus direalisasikan agar layanan elektronik yang dikembangkan itu 
dapat dimanfaatkan efektif, efisien, dan real time.

IKU No. 5a-CP Persentase Penyelesaian Aplikasi e-Prime.

Aplikasi e-Prime dimaksudkan sebagai sistem informasi layanan berbasis e-corporate yang merupakan sistem informasi core application Setjen. Aplikasi ini digunakan oleh seluruh unit di Kementerian Keuangan. Aplikasi e-Prime telah diselesaikan bertahap, yakni 14 aplikasi prioritas yang mencakup Aplikasi Integrated Budgeting System dan E_SIMBA (untuk Biro Perencanaan Keuangan), Aplikasi EJobs (Knowledge Management OTL) (untuk Organta), Aplikasi SIMBANKUM (untuk bantuan hukum), Kemenkeulib/Aplikasi
Perpustakaan dan Sistem Informasi PPID (untuk Biro Komunikasi dan Layanan Informasi), Aplikasi ULP/SI Manajemen Layanan Pengadaan (untuk pengadaan barang/jasa), Perjadin Dalam Negeri dan Notifikasi Hak-Hak Keuangan Pegawai (untuk Biro Umum), SIPeLanTIK/Sistem Informasi Pengelolaan TIK (untuk Pusintek sendiri), E-Licensing Akuntan Publik (untuk pembinaan profesi), DAMS Next Generation (untuk Pushaka), Aplikasi SIMAPAN dan SIMAPIK.

Tabel 4 menunjukkan sasaran strategis terwujudnya sistem informasi manajemen dan kepuasan layanan TIK beserta capaian IKU-nya masing-masing.

Tabel 4 Sasaran Reformasi Birokrasi Transformasi Kelembagaan dan Pengembangan SIM beserta Capaian IKU

\begin{tabular}{|c|c|c|c|c|}
\hline Kode & Sasaran Strategis/ & \multirow{2}{*}{ Target } & \multirow{2}{*}{ Realisasi } & \multirow{2}{*}{ Nilai } \\
\hline SS/IKU & Indikator Kinerja Utama (IKU) & & & \\
\hline \multicolumn{4}{|c|}{ Internal Process Perspective (30\%) } & 33.52 \\
\hline 4 & RBTK Bidang TIK yang Efektif, Efisien, & an Kredi & & 100 \\
\hline $4 \mathrm{a}-\mathrm{N}$ & $\begin{array}{llr}\text { Persentas } & \text { Implementasi } & \text { Inisiatif } \\
\text { Transformasi Kelembagaan Bidang TIK }\end{array}$ & $100 \%$ & $100 \%$ & 100 \\
\hline 5 & Pengembangan Sistem Informasi yang Te & integrasi & & 118.57 \\
\hline $5 \mathrm{a}-\mathrm{CP}$ & $\begin{array}{l}\text { Persentase Penyelesaian Aplikasi e- } \\
\text { Prime }\end{array}$ & $100 \%$ & $118.57 \%$ & 118.57 \\
\hline
\end{tabular}

6. Sasaran Strategis Pengelolaan TIK yang Andal

$\begin{array}{lrr}\text { Pengelolan } & \text { TIK yang andal } \\ \text { merupakan } & \text { penyediaan } & \text { dan }\end{array}$


pemenuhan layanan TIK, serta pada Katalog Layanan meliputi 20 penyelesaian gangguan layanan TIK layanan. Norma waktu layanan yang andal kepada pengguna layanan TIK sesuai ketentuan yang disepakati pada Katalog Layanan dan/atau service level agreement. Berikut ini IKU terkait pengelolaan TIK yang andal.

IKU No. 6b-N Persentase Pencapaian Layanan pada Katalog Layanan.

Katalog Layanan merupakan daftar layanan TIK yang dimiliki Pusintek. adalah standar waktu pemenuhan layanan sesuai SOP yang terlampir pada Katalog Layanan. Persentase pencapaian layanan pada Katalog Layanan adalah rata-rata persentase pencapaian jenis layanan pada Katalog Layanan yang sesuai dengan norma waktu. Persentase pencapaian layanan terhadap ketentuan yang disepakati pada Katalog Layanan sesuai norma waktu diperoleh dengan Layanan terhadap hal yang disepakati perhitungan:

Capaian $=\frac{\text { Jumlah permintaan layanan yang sesuai norma waktu }}{\text { Jumlah permintaan layanan terhadap ketentuan yang disepakati }} x 100$

Data menunjukkan bahwa jumlah waktu 1.469. dengan demikian, hanya permintaan layanan disepakati awal periode 1.470, sedangkan yang satu layanan diselesaikan melebihi berhasl diselesaikan sesuai norma norma waktu (lihat Tabel 5).

Tabel 5 Jumlah Tiket Layanan TIK

\begin{tabular}{llc}
\hline No & \multicolumn{1}{c}{ Jenis Layanan } & $\begin{array}{c}\text { Jumlah } \\
\text { Tiket }\end{array}$ \\
\hline 1 & $\begin{array}{l}\text { Jumlah permintaan layanan atau hal yang ditentukan pada } \\
\text { Katalog Layanan }\end{array}$ & 1.470 \\
\hline 2 & $\begin{array}{l}\text { Jumlah permintaan layanan yang sesuai norma waktu } \\
\text { layanan }\end{array}$ & 1.469 \\
\hline 3 & $\begin{array}{l}\text { Jumlah permintaan layanan yang melebihi norma waktu } \\
\text { layanan }\end{array}$ & 1 \\
\hline
\end{tabular}

7. Sasaran Strategis Pembinaan dan Pengelolaan Jabatan Fungsional
Pranata Komputer yang

Profesional 


\begin{abstract}
Jabatan fungsional terkait pengelolaan TI yakni Pranata Komputer di lingkup Kementerian Keuangan dikelola oleh Pusintek. Dalam pelaksanaan tugasnya, Pusintek harus bersikap profesional dalam melakukan pembinaan dan koordinasi pengelolaan administrasi jabatan fungsional tersebut maupun pengembangan kompetensinya. Berikut ini IKU terkait pembnaan jabatan fungsional.
\end{abstract}

\section{IKU No. 7a-N Persentase}

\section{Efektivitas Bimbingan Teknis Bagi}

Tim Penilai Instansi Pusat.

Bimbingan teknis bagi Tim Penilai Instansi Pusat (TPIP) adalah bimbingan teknis yang dilaksanakan kepada TPIP dalam rangka meningkatkan kompetensi dan pemahaman TPIP terhadap persyaratan penilaian kegiatan kepranataan. Kegiatan bimbingan teknis bagi TPIP dilaksanan di Pusintek dengan melibatkan pemateri dari BPS atau unit lain sesuai dengan kompetensi yang dibutuhkan. Adapun kegiatan tersebut dinilai efektif apabila nilai post test TPIP yang mengikuti bimbingan teknis memenuhi passing grade yang ditentukan yaitu 70. Berdasarkan hasil post test, seluruh tim penilai yang mengikuti bimbingan teknis mendapatkan nilai di atas 70. Tabel 6 menunjukkan sasaran strategis pengelolaan TIK dan pembinaan jabatan fungsional beserta capaian IKU-nya masing-masing.

Tabel 6 Sasaran Strategis Pengelolaan TIK dan Pembinaan Jabatan Fungsional beserta Capaian IKU

\begin{tabular}{|c|c|c|c|c|c|}
\hline Kode & \multicolumn{2}{|c|}{ Sasaran Strategis/ } & Target & Realisasi & Nilai \\
\hline SS/IKU & \multicolumn{2}{|c|}{ Indikator Kinerja Utama (IKU) } & & & \\
\hline \multicolumn{3}{|c|}{ Stakeholder Perpective (25\%) } & & & 30.00 \\
\hline 6 & \multicolumn{2}{|c|}{ Pengelolaan TIK yang Andal } & & & 108.38 \\
\hline $6 \mathrm{a}-\mathrm{N}$ & \multicolumn{2}{|c|}{$\begin{array}{l}\text { Persentase Pemutakhiran Database Aset } \\
\text { TIK Tahap I }\end{array}$} & $20 \%$ & $120 \%$ & 120 \\
\hline $6 b-N$ & \multicolumn{2}{|c|}{$\begin{array}{l}\text { Persentase Pencapaian Layanan pada } \\
\text { Katalog Layanan }\end{array}$} & $98 \%$ & $99,92 \%$ & 101.96 \\
\hline $6 c-N$ & $\begin{array}{l}\text { Persentase } \\
\text { Konfigurasi } \\
\text { Kemenkeu }\end{array}$ & $\begin{array}{rr}\text { Penerapan } & \text { Baseline } \\
\text { Keamanan } & \text { Informasi }\end{array}$ & $100 \%$ & $100 \%$ & 100 \\
\hline 7 & \multicolumn{4}{|c|}{$\begin{array}{l}\text { Pembinaan dan Pengelolaan Jabatan Fungsional Pranata } \\
\text { Komputer yang Profesional }\end{array}$} & 120 \\
\hline
\end{tabular}




$\begin{array}{llllll}7 \mathrm{a}-\mathrm{N} & \begin{array}{l}\text { Persentase } \\ \text { Teknis bagi Tim Penilai Instansi Pusat }\end{array} & \begin{array}{l}\text { Efektivitas } \\ \text { Tekn }\end{array} & \begin{array}{c}\text { Bimbingan } \\$\cline { 2 - 5 }\end{array} & $100 \% & 120\end{array}$

Berdasarkan Tabel 6, target IKU untuk sasaran strategis pengelolaan TIK dan pembinaan jabatan fungsional tercapai. Ini menunjukkan perspektif pemangku kepentingan (layanan) pada pihak lain terwujud dengan baik.

8. Sasaran Strategis Sumber Daya Manusia yang Kompetitif Yang dimaksud SDM kompetitif adalah SDM yang memiliki sikap, pengetahuan, dan keterampilan yang dipersyaratkan dalam melaksanakan tuntutan organisasi. Berikut ini beberapa IKU SDM kompetitif.

\section{IKU No. 8a-N Persentase}

Pemenuhan

Pengembangan

\section{Kompetensi.}

Standar jam pelatihan digunakan sebagai acuan dalam penentuan jumlah paling sedikit jam pelatihan yang dipenuhi oleh tiap personel selama periode satu tahun. Satu jamlat adalah 45 menit. Standar jamalt minimal pertahun per pegawai adalah total 24 jamlat.

Kegiatan pengembangan SDM yang telah dilakukan oleh Pusintek adalah mengirimkan pegawai untuk mengikuti diklat, workshop, atau seminar baik yang diselenggarakan oleh Kementerian Keuangan atau pihak eksternal. Selain itu, Pusintek melakukan pula capacity building, training softskill, dan transfer knowledge. Kegiatan-kegiatan tersebut cukup efektif untuk mengembangkan SDM di Pusintek. Dari 364 pegawai, yang berhasil merealisasikan pemenuhan jamlat sebesar $99 \%$ dari target $80 \%$.

9. Sasaran Strategis Organisasi yang Tepat Sesuai Maksud (Kegunaan) atau Fit for Purpose

Tujuan organisasi merupakan hasil yang ingin dicapai. Untuk mencapainya, struktur dan perangkat organisasi harus mendukung. Maka, organisasi fit for purpose diperlukan karena mengakomodasi program dan kegiatan untuk mencapai tujuan organisasi Sekretariat Jenderal. Hal ini bisa terwujud dengan penyadaran bahwa organisasi beserta proses bisnis pelaksanaan tugas dan fungsi bisa menyesuaikan kebutuhan dan dinamika organisasi dan transformasi kelembagaan. Berikut ini IKU yang relevan. 
IKU No. 9a-N Indeks Kesehatan Organisasi.

Indeks Kesehatan Organisasi

Kementerian Keuangan atau lazim dikenal sebagai Ministry of Finance Organizational Fitness Index (MOFIN) merupakan parameter guna mengetahui seberapa sehat dan berkinerja tinggi sebagai umpan balik bagi perbaikan organisasi. Hasil survei MOFIN menunjukkan Pusintek berada pada skor 89 (baik). 10. Sasaran Strategis Otomasi Layanan Korporat (e-Prime)

Secretariat Jenderal terus berupaya melakukan otomasi layanan agar terwujud e-Government. Layanan berbasis elektronik yang digunakan dimonitor agar terus akurat dan real time. Berikut ini IKU yang relevan.

\section{IKU No. 10a-N Tingkat}

Pengembangan Aplikasi e-Prime Tahap III.

e-Prime ini terus dikembangkan karena dijadikan sebagai sistem informasi layanan berbasis elektronik. Konten SI ini mencakup aplikasi-aplikasi milik Sekretriat Jenderal yang dimanfaatkan oleh unit Kemenkeu. Tentu saja, aplikasiaplikasi tersebut diprioritaskan pengembangannya agar lebih bermanfaat bagi peningkatan kinerja unit-unit pemakai. Tingkat penyelesaian e-Corporate Services yang menjadi tanggung jawab Pusintek meliputi dokumen Business Process Re-engineering (BPR), dokumen User Requirement (UR), dan User Acceptance Test (UAT) dan Quality Assurance (QA). Berdasarkan kegiatan yang menjadi tanggung jawab Pusintek, realisasi IKU tingkat pengembangan aplikasi e-Prime tahap III mencapai target sebesar $100 \%$.

11. Sasaran Strategis Pengelolaan Anggaran yang Optimal

Anggaran juga merupakan instrumen pendukung yang harus dikelola optimal. Pengelolaan anggaran optimal menerapkan prinsip efisien, hemat, dan tidak mewah, serta akuntabel. Di samping itu, optimalisasi anggaran dilakukan agar keluaran kegiatan terwujud sesuai perencanaan pada Daftar Isian Pelaksanaan Anggaran (DIPA). IKU yang relevan sebagai berikut.

IKU No. 11a-CP Persentase Kualitas Pelaksanaan Anggaran.

Ruang lingkup pengukuran IKU ini mencakup penyerapan anggaran, efisiensi, dan pencapaian 


\section{Praktik Balanced Scorecard Sektor Publik: Sistem Pengukuran Kinerja untuk Meningkatkan Performa Organisasi}

keluaran/output. Penyerapan anggaran dipandang penting karena menunjukkan belanja program dan kegiatan dijalankan. Rumus persentase penyerapan anggaran adalah membagi realisasi anggaran nonbelanja pegawai dengan pagu anggaran nonbelanja pegawai. Cara dan formulasi pengukuran IKU terkait pelaksanaan anggaran lebih rinci diuraikan dalam Surat Edaran No. 32 (2015) yang mengatur tata cara pengukuran penyerapan anggaran lingkup Kemenkeu. Tabel 7 menunjukkan sasaran strategis SDM, organisasi, dan anggaran beserta capaian IKU-nya masing-masing.

Tabel 7 Sasaran Strategis SDM, Organisasi, dan Anggaran beserta Capaian IKU

\begin{tabular}{|c|c|c|c|c|}
\hline Kode & Sasaran Strategis/ & \multirow{2}{*}{ Target } & \multirow{2}{*}{ Realisasi } & \multirow{2}{*}{ Nilai } \\
\hline $\mathrm{SS} / \mathrm{IKU}$ & Indikator Kinerja Utama (IKU) & & & \\
\hline \multicolumn{2}{|c|}{ Learning and Growth Perspective (30\%) } & & & 35.19 \\
\hline 8 & SDM yang Kompetitif & & & 120 \\
\hline $8 \mathrm{a}-\mathrm{N}$ & $\begin{array}{l}\text { Persentase Pemenuhan Pengembangan } \\
\text { Kompetensi }\end{array}$ & $80 \%$ & $90 \%$ & 120 \\
\hline $8 b-N$ & $\begin{array}{l}\text { Persentase Implementasi Dialog Kinerja } \\
\text { Individu }\end{array}$ & $50 \%$ & $100 \%$ & 120 \\
\hline 9 & Organisasi yang Fit for Purpose & & & 117.41 \\
\hline $9 \mathrm{a}-\mathrm{N}$ & Indeks Kesehatan Organisasi & 78 & 89 & 114.10 \\
\hline $9 b-N$ & Indeks Penyusunan Proses Bisnis & 100 & 132.26 & 120 \\
\hline 10 & Otomasi Layanan Korporat (e-Prime) & & & 120 \\
\hline $10 \mathrm{a}-\mathrm{N}$ & $\begin{array}{l}\text { Tingkat Pengembangan Aplikasi } e- \\
\text { Prime Tahap III }\end{array}$ & $100 \%$ & $100 \%$ & 120 \\
\hline 11 & Pengelolaan Anggaran Optimal & & & 111.78 \\
\hline $11 \mathrm{a}-\mathrm{CP}$ & $\begin{array}{lll}\text { Persentase } & \text { Kualitas } & \text { Pelaksanaan } \\
\text { Anggaran } & & \\
\end{array}$ & $95 \%$ & $102.48 \%$ & 107.87 \\
\hline $11 \mathrm{~b}-\mathrm{N}$ & Persentase Realisasi Pengadaan & $85 \%$ & $100 \%$ & 117.65 \\
\hline
\end{tabular}

Berdasarkan Tabel 7, target IKU di bidang SDM, organisasi, dan anggaran tercapai dengan baik. Hal ini menunjukkan Pusintek mampu mewujudkan capaian IKU dari perspektif learning and growth. Perspektif ini mengukur daya dukung organisasi sehingga tugas dan fungsi dijalankan dengan baik. Hal ini selaras dengan studi bahwa perspektif learning and growth memiliki korelasi kuat terhadap pencapaian pengukuran kinerja organisasi 
(Chimtengo, Stephen, Mkandawire, \& Hanif, 2017).

\section{SIMPULAN}

Berdasarkan uraian dan pembahasan, ditarik simpulan bahwa Kementerian Keuangan merupakan organisasi publik yang mengadopsi Balanced Scorecard dalam pengelolaan kinerja. Berbeda dengan sektor privat, Pusintek Kementerian Keuangan menyesuaikan adopsi Balanced Scorecard pada perspektif stakeholder atau customer, proses bisnis internal, dan pembelajaran \& pertumbuhan, mengesampingkan perspektif financial karena memang institusi publik berfokus pada layanan ketimbang laba komersial. Adapun hasil analisis terhadap penerapan

\section{DAFTAR PUSTAKA}

Ayoup, Hazeline, Normah Omar, \& Ibrahim Kamal Abdul Rahman. (2016). "Balanced Scorecard and Strategic Alignment: A Malaysian Case". International Journal of Economics and Financial Issues, 2016, 6(S4) 85-95.
Balanced Scorecard pada Pusintek mengindikasikan bahwa Balanced Scorecard membantu mengelola kinerja organisasi. Hal ini selaras dengan studi (Sahiti, Arben, Ahmeti, Sahiti, \& Aliu, 2016) bahwa Balanced Scorecard meningkatkan kinerja dan profitabilitas organisasi. Pencapaian nilai kerja organisasi (NKO) sebesar 115,10 menunjukan bahwa kinerja Pusintek dalam tahun berjalan cukup baik. NKO Pusintek yang tinggi tersebut berhasil diraih karena kedua puluh IKU Pusintek dapat terealisasi sesuai dan/atau melebihi target yang telah ditetapkan. Capaian tersebut menjadi dasar bagi perbaikan atau peningkatan kinerja mendatang.

Chimtengo, Stephen, Kezzie Mkandawire, and Rabiya Hanif. (2017). “An Evaluation of Performance Using the Balanced Scorecard Model for the University of Malawi's Polytechnic". African Journal of Business Management. Vol. 
11(4), pp. 84-93. DOI:

10.5897/AJBM2016.8201.

Hidayat, Suryo, M. Syamsul Maarif,

Mukhamad Najib. (2017).

"Determination of Key

Performance Indicator with

Balanced Scorecard Approach

in Public Sector". Jurnal

Aplikasi Manajemen. Vol 15,

No 2 (2017).

DOI: http://dx.doi.org/10.2177

6/ub.jam.2017.015.02.13.

Instruksi Presiden Republik

Indonesia Nomor 5 Tahun 2004

tentang

Percepatan

Pemberantasan Korupsi.

Jones, Phil. (2017). "Leading

Indicators and Lagging

Indicators - Making Sense of

Them".

https://www.excitant.co.uk.

Keputusan Menteri Keuangan

Republik Indonesia Nomor

467/KMK.01/2014 tentang

Pengelolaan Kinerja di

Lingkungan Kementerian

Keuangan.

Ondrej Zizlavsky. (2014). "The

Balanced Scorecard: Innovative

Performance Measurement and

Management Control System.”
Journal of Technology

Management \& Innovation.

2014, Volume 9, Issue 3. DOI:

10.4067/S0718-

27242014000300016.

Peraturan Menteri Keuangan

Republik Indonesia Nomor

234/PMK.01/2015 tentang

Organisasi dan Tata Kerja

Kementerian Keuangan.

Peraturan Presiden Republik

Indonesia Nomor 81 Tahun

2010 tentang Grand Design

Reformasi Birokrasi 2010-

2025.

Rafiq, Muhammad Rafiq, XingPing Zhang, Jiahai Yuan, Shumaila Naz, \& Saif Maqbool. (2020). "Impact of a Balanced Scorecard as a Strategic Management System Tool to Improve Sustainable Development: Measuring the Mediation of Organizational Performance through PLSSmart”. Sustainability 12, 1365; DOI:10.3390/su12041365.

Sahiti, Arben, Skender Ahmeti, Arbana Sahiti, Muhamet Aliu. (2016). "The Impact of Balanced Scorecard on 
Improving the Performance and

Profitability of the

Implementing Companies".

DOI: 10.5901/mjss.2016.v7n4p60.

Senaratha, S.A.C.L. \& S.S.J. Patabendige. (2015). "Balance Scorecard: Translating Corporate Plan into Action. A Case Study on University of Kelaniya, Sri Lanka”. Procedia-Social and

Behavioral Sciences (2015) 278 -285 .

Taufik, Abd Rahman, Ali Djamhuri, \& Erwin Saraswati. (2018). "Performance Measurement Using Balanced Scorecard (BSC) (Study at Hospitals in
Mediterranean Journal of

Social Sciences. Vol 7 No 4.

Pasuruan)". Journal of Accounting and Business Education, 3 (I) September 2018.

Türüdüoğlu, Figen, Nilüfer Suner, and Gülçin Yildırım. (2014). "Determination of goals under four perspectives of balanced scorecards and linkages between the perspectives: A survey on luxury summer hotels in Turkey". Procedia-Social and Behavioral Sciences (2014) $372-377$. 